\title{
Failure
}

\section{of dihydroartemisinin-piperaquine treatment of uncomplicated Plasmodium falciparum malaria in a traveller coming from Ethiopia}

\author{
Federico Gobbi ${ }^{* *}$, Dora Buonfrate ${ }^{1}$, Michela Menegon², Gianluigi Lunardi , Andrea Angheben ${ }^{1}$, Carlo Severini ${ }^{2}$,
} Stefania Gori ${ }^{1}$ and Zeno Bisoffi ${ }^{1}$

\begin{abstract}
Background: Artemisinin combination therapy (ACT) is used worldwide as the first-line treatment against uncomplicated Plasmodium falciparum malaria. Despite the success of ACT in reducing the global burden of malaria, the emerging of resistance to artemisinin threatens its use.

Case report: This report describes the first case of failure of dihydroartemisinin-piperaquine (DHA-PPQ) for the treatment of $P$. falciparum malaria diagnosed in Europe. It occurred in an Italian tourist returned from Ethiopia. She completely recovered after the DHA-PPQ treatment but 32 days after the end of therapy she had a recrudescence. The retrospective analysis indicated a correct DHA-PPQ absorption and genotyping demonstrated that the same $P$. falciparum strain was responsible for the both episodes.
\end{abstract}

Conclusion: In consideration of the growing number of cases of resistance to ACT, it is important to consider a possible recrudescence, that can manifest also several weeks after treatment.

Keywords: Dihydroartemisinin-piperaquine (DHA-PPQ), Failure, Plasmodium falciparum, Recrudescence

\section{Background}

Artemisinin combination therapy (ACT) is used worldwide as the first-line treatment against uncomplicated falciparum malaria [1]. Dihydroartemisinin-piperaquine (DHA-PPQ) is characterized by a post-treatment prophylactic effect against re-infections that is longer than artemether-lumefantrine [2]. Despite the success of ACT in reducing the global burden of malaria, the emergence of resistance to artemisinin threatens its use. In Cambodia, failure of ACT is now frequently observed [3, 4]. The increase of treatment failures and parasite clearance times observed soon after the widespread introduction of DHA-PPQ suggests a rapid emergence of resistance to

\footnotetext{
*Correspondence: federico.gobbi@sacrocuore.it

${ }^{1}$ Centre for Tropical Diseases, Hospital Sacro Cuore-Don Calabria, Via Sempreboni 5, Negrar, 37024 Verona, Italy

Full list of author information is available at the end of the article
}

both artemisinin and piperaquine components. In Asia, treatment failures have been reported in Myanmar [5]. In South America, data on (good) efficacy of DHA-PPQ is based on only one trial, conducted in Peru between 2003 and 2005 [6]. In Africa, trials conducted in Burkina Faso [7], Kenya [8] and Angola [9] showed that DHA-PPQ was highly effective, with very rare cases of recrudescence invariably within 28 days.

\section{Case report}

A 72-year-old Italian woman was admitted on 26 November, 2014 to the Centre for Tropical Diseases (CTD) of Negrar (Verona), for myalgias and arthralgias since 2 days, fever (up to $40^{\circ} \mathrm{C}$ ) and nausea since one day. She had visited Ethiopia (Omo River Valley) from 6 to 18 November 2014. She was vaccinated against yellow fever, hepatitis A and B, but had not taken any malaria chemoprophylaxis. Her travel history included Ethiopia, Niger, 
India, and Nambia, not South East Asia. Upon admission, her temperature was $38.3^{\circ} \mathrm{C}$, her weight $67.5 \mathrm{~kg}$. Physical examination was unremarkable. The blood tests showed white blood cells (WBCs) $3.85 \times 10^{9} / \mathrm{L}$ (normal range $5.2-12.4 \times 10^{9} / \mathrm{L}$ ), haemoglobin $(\mathrm{Hb}) 12.5 \mathrm{~g} / \mathrm{dL}$ (normal range $14-18 \times \mathrm{g} / \mathrm{dL}$ ), platelets $46 \times 10^{9} / \mathrm{L}$ (normal range $130-400 \times 10^{9} / \mathrm{L}$ ), C-reactive protein $135 \mathrm{mg} / \mathrm{L}$ (normal range $0-5 \mathrm{mg} / \mathrm{L}$ ), procalcitonin $14 \mu \mathrm{g} / \mathrm{L}$ (normal range $0-0.5 \mu \mathrm{g} / \mathrm{L})$. The quantitative buffy coat (QBC) test, antigen malarial test and blood smears resulted positive for Plasmodium falciparum, with a parasitaemia of $0.3 \%$ $(14,600 / \mu \mathrm{L})$. The patient was treated with DHA-PPQ $320 / 40 \mathrm{mg}$, three tablets/day for 3 days. The first day after treatment the parasitaemia dropped to $0.0023 \%(96 / \mu \mathrm{L})$. After two days, the blood films and the QBC test resulted negative. Also, iv ceftriaxone $2 \mathrm{~g} /$ day was administrated for a left basal bronchopneumonia. The patient was discharged on 5 December, 2014.

At a follow-up visit on 23 December, the QBC test and blood smears were still negative. The blood tests showed WBC $7.98 \times 10^{9} / \mathrm{L}, \mathrm{Hb} 11.8 \mathrm{~g} / \mathrm{dL}$, platelets $233 \times 10^{9} / \mathrm{L}$.

She was re-admitted on 7 January, 2015 complaining of fever, nausea and vomiting that had started 7 days before (more than 4 weeks after anti-malaria treatment). The QBC test, antigen malarial test and blood smears all resulted positive again for falciparum malaria, with a parasitaemia of $0.4 \%(12,100 / \mu \mathrm{L})$. WBCs were $5.5 \times 10^{9} / \mathrm{L}$, $\mathrm{Hb} 9.5 \mathrm{~g} / \mathrm{dL}$, platelets $96 \times 10^{9} / \mathrm{L}$. The patient was treated this time with atovaquone-proguanil $250 / 100 \mathrm{mg}$, four tablets/day for 3 days. The parasitaemia decreased to $0.36 \%(10,930 / \mu \mathrm{L}) 24 \mathrm{~h}$ after first dose of treatment, $0.16 \%(5017 / \mu \mathrm{L})$ the second day, $0.0016 \%(46 / \mu \mathrm{L})$ the third day. After 4 days, blood films resulted negative. The patient was discharged on 12 January, 2015.

At follow-up visits 28 and 56 days after the second malaria episode, QBC and blood smears resulted negative and the main laboratory findings were normal.

The malaria-PCR performed a posteriori on a blood specimen collected on 23 December, 2014 resulted positive. Serum DHA-PPQ concentrations were retrospectively evaluated on cryo-preserved $\left(-80{ }^{\circ} \mathrm{C}\right)$ samples taken on different days, during and after the drug administration, coupled with tandem-mass spectrometry (Table 1). Limits of quantification for DHA and PPQ were 0.31 and $12.5 \mathrm{ng} / \mathrm{mL}$, respectively. Pharmacokinetic data after the last dose of the three-day course of DHA and PPQ were comparable to data published by Nguyen et al. [10] indicating no defect in drug absorption. PPQ serum concentration on day 7 was calculated on the basis of the drug elimination half-life in this patient. Calculated PPQ concentrations on day 7 showed a serum level of $110 \mathrm{ng} / \mathrm{mL}$ (levels below $30 \mathrm{ng} / \mathrm{mL}$ have been associated to a higher risk of recurrence of malaria) [11].

Genotyping of P. falciparum isolate(s) responsible for the patient's infection was performed by amplification of three polymorphic markers, the merozoite surface protein $1(m s p 1)$, merozoite surface protein $2(m s p 2)$, and glutamate-rich protein ( lurp) genes. These genes show a length polymorphism, allowing the detection of multiple infections by different P. falciparum genotypes [12, 13]. Total genomic DNAs were extracted using PureLink Genomic DNA Kits-Invitrogen, from $200 \mu \mathrm{l}$ of whole infected blood samples collected from the patient at the first (27 November, 2014) and second (7 January, 2015) hospital admittances. PCR amplified for $m s p 1 / m s p 2$ and for glurp as described by Wooden et al. [12] and Viriyakosol et al. [13], respectively. Genetic characterization of the $P$. falciparum isolates showed the presence of a single isolate responsible for the first episode and for the recurrence (Fig. 1). In order to investigate the resistance to the anti-malarial drugs of the isolate of $P$. falciparum infecting the patient, PCR amplification and sequencing were performed, in order to evaluate the presence of point mutations in the six molecular markers of $P$. falciparum (PfK13, Pfcrt, Pfmdr1, Pfdhfr, Pfdhps and PfCytB genes) linked to resistance to the artemisinin derivatives, quinolines, antifolates-cycloguanil and atovaquone. The polymorphism of the propeller domain of the $P f k 13$ gene

Table 1 Serum concentrations of dihydroartemisinin-piperaquine

\begin{tabular}{lllc}
\hline & Piperaquine $(\mathbf{n g} / \mathbf{m L})$ & Dihydroartemisinin $(\mathbf{n g} / \mathbf{n L})$ & Hours since last administration \\
\hline Day 1 & 132 & 0.74 & 10 \\
Day 2 & 282 & 0.34 & 15 \\
Day 3 & 234 & 1.34 & 15 \\
Day 4 & 205 & .v. & 39 \\
Day 5 & 131 & - & 63 \\
Day 28 & 18 & - & 591 \\
Day 7 (calculated) & 110 & & 111 \\
\hline
\end{tabular}




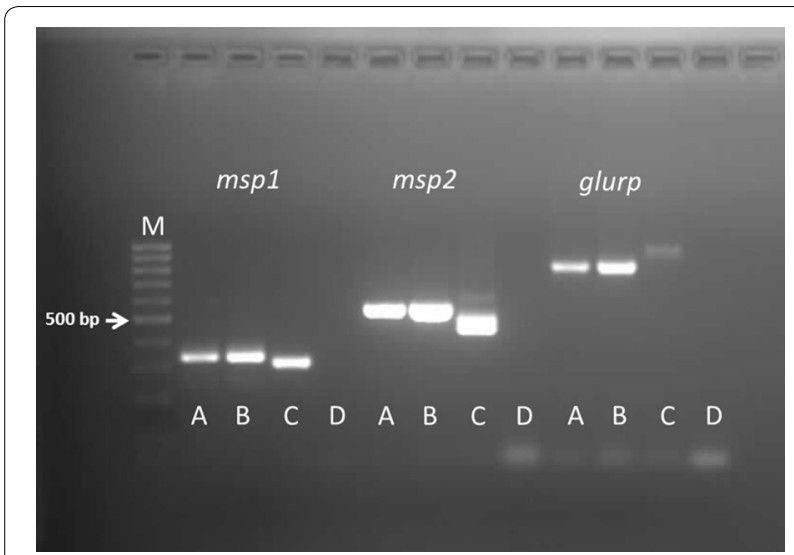

Fig. 1 Genotyping of Plasmodium falciparum isolates responsible for the patient's infection. M DNA ladder; $A$ sample November 27, 2014; $B$ sample January 7, 2015; C positive control; $D$ negative control

was assessed as described by Taylor et al. [14]. Analysis of Pfcrt/Pfdhps and Pfmdr1 and genes was performed as previously described in Menegon et al. [15] and Duraisingh et al. [16], respectively. A fragment of Pfdhfr gene spanning codons 51-108 was analysed as described by Palmieri et al. [17]. The presence of point mutation in PfCytB gene was evaluated as described in Korsinczky et al. [18]. All PCR products were sent to Eurofins Genomics Company (Germany) for sequencing. The obtained sequences were compiled and analysed by Accelrys DS Gene software. The results are summarized in Table 2. Analysis of polymorphism of the P. falciparum isolates showed the presence of mutations in Pfcrt and $P f m d r 1$ genes linked to resistance to the quinolines and mutation in Pfdhfr and Pfdhps genes correlated to antifolate/cycloguanil resistance. No mutations associated with artemisinin resistance and atovaquone were detected.

\section{Conclusion}

This is the first case of failure of DHA-PPQ reported in Europe. The patient returned from Ethiopia, a country where DHA-PPQ failures have not been reported before. In this case, the rapid response to DHA-PPQ and the lack of mutations in the PfK 13 gene suggest the involvement of an artemisinin-sensitive strain. Although it was not possible to analyse a specific molecular marker of resistance to PPQ (a newly identified gene, PFE1085w is presumably associated to resistance to this drug) [19], the combination of results obtained from molecular and pharmacokinetic analyses and the clinical characteristics support that the strain was resistant to the PPQ component.

In the last 2 years (July 2014 to June 2016) DHA-P was administered to 36 patients attended at the CTD for falciparum malaria, observing no other failure. These data are in agreement with the literature. The efficacy of DHAPPQ has been found very high, particularly in the African continent. There was a relevant delay between the onset of symptoms and the second diagnosis because the index of suspicion was low due to the negative laboratory tests performed at the 28-day follow-up visit. In consideration of the growing number of cases of resistance to $\mathrm{ACT}$, it is important to consider a possible recrudescence, which can manifest several weeks after treatment.

Table 2 Analysis of the molecular markers of $P$. falciparum linked to drug resistance

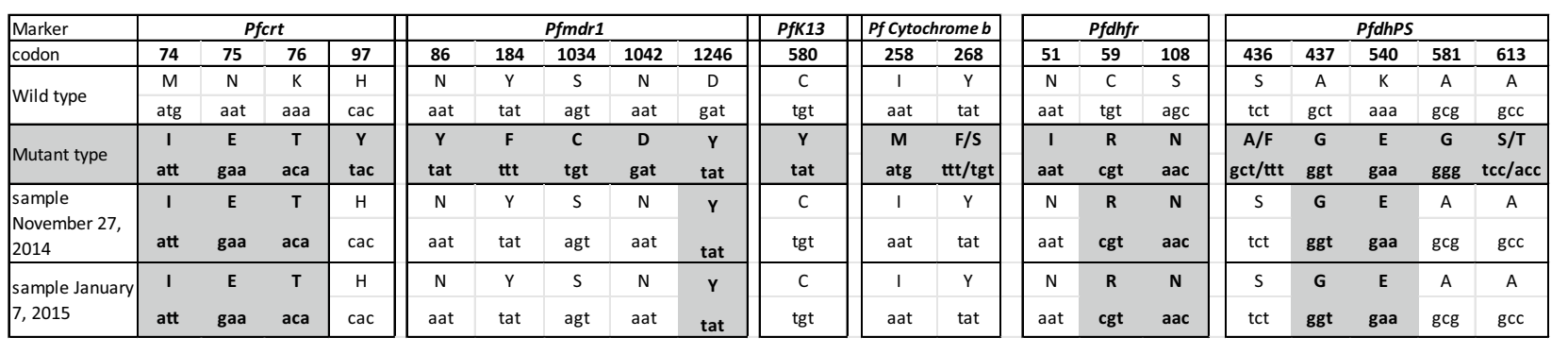

Specific point mutations in Pfcrt and Pfmdr1 gene are linked to quinoline-based antimalarial resistance; $P f K 13$ is the molecular markers for artemisinin resistance; mutation $1258 \mathrm{M}$ and $\mathrm{Y} 268 \mathrm{~F} / \mathrm{S}$ in PfCytB gene are linked to atovaquone resistance; mutations in Pfdhfr/Pfdhps genes are responsible for $P$. falciparum resistance to antifolate-cycloguanil 


\section{Authors' contributions}

FG, DB and ZB drafted the manuscript. FG, DB and AA collected clinical and laboratory data. MM and CS performed the molecular tests. GL and SG were responsible for the pharmacokinetic analysis. All authors commented and agreed upon the final manuscript. All authors read and approved the final manuscript.

\section{Author details}

'Centre for Tropical Diseases, Hospital Sacro Cuore-Don Calabria, Via Sempreboni 5, Negrar, 37024 Verona, Italy. ${ }^{2}$ Department of Infectious, Parasitic and Immunomediated Diseases (MIPI), Istituto Superiore di Sanità, Viale Regina Elena, 299, 00161 Rome, Italy.

\section{Acknowledgements}

None.

\section{Competing interests}

The authors declare that they have no competing interests.

\section{Consent for publication}

Written informed consent for the publication of the present case was obtained from the patient.

Received: 15 July 2016 Accepted: 16 October 2016

Published online: 03 November 2016

\section{References}

1. Nguyen TD, Olliaro P, Dondorp AM, Baird JK, Lam HM, Farrar J, et al. Optimum population-level use of artemisinin combination therapies: a modelling study. Lancet Glob Health. 2015;3:e758-66.

2. Pfeil J, Borrmann S, Bassat Q, Mulenga M, Talisuna A, Tozan Y. An economic evaluation of the posttreatment prophylactic effect of dihydroartemisinin-piperaquine versus artemether-lumefantrine for first-line treatment of Plasmodium falciparum malaria across different transmission settings in Africa. Am J Trop Med Hyg. 2015;93:961-6.

3. Saunders DL, Vanachayangkul P, Lon C. Dihydroartemisinin-piperaquine failure in Cambodia. N Engl J Med. 2014;371:484-5.

4. Amaratunga C, Lim P, Suon S, Sreng S, Mao S, Sopha C, et al. Dihydroartemisinin-piperaquine resistance in Plasmodium falciparum malaria in Cambodia: a multisite prospective cohort study. Lancet Infect Dis. 2016;16:357-65.

5. Tun KM, Jeeyapant A, Imwong M, Thein M, Aung SS, Hlaing TM, et al. Parasite clearance rates in Upper Myanmar indicate a distinctive artemisinin resistance phenotype: a therapeutic efficacy study. Malar J. 2016:15:185.

6. Grande T, Bernasconi A, Erhart A, Gamboa D, Casapia M, Delgado C, et al. A randomised controlled trial to assess the efficacy of dihydroartemisininpiperaquine for the treatment of uncomplicated falciparum malaria in Peru. PLoS ONE. 2007;2:e1101.
7. Zongo I, Somé FA, Somda SA, Parikh S, Rouamba N, Rosenthal PJ, et al. Efficacy and day 7 plasma piperaquine concentrations in African children treated for uncomplicated malaria with dihydroartemisinin-piperaquine. PLoS ONE. 2014;9:e103200.

8. Agarwal A, McMorrow M, Onyango P, Otieno K, Odero C, Williamson J, et al. A randomized trial of artemether-lumefantrine and dihydroartemisinin-piperaquine in the treatment of uncomplicated malaria among children in western Kenya. Malar J. 2013;12:254.

9. Plucinski MM, Talundzic E, Morton L, Dimbu PR, Macaia AP, Fortes F, et al. Efficacy of artemether-lumefantrine and dihydroartemisinin-piperaquine for treatment of uncomplicated malaria in children in Zaire and Uíge provinces, Angola. Antimicrob Agents Chemother. 2015;59:437-43.

10. Nguyen DV, Nguyen QP, Nguyen ND, Le TT, Nguyen TD, Dinh DN, et al. Pharmacokinetics and ex vivo pharmacodynamics antimalarial activity of dihydroartemisinin-piperaquine in patients with uncomplicated falciparum malaria in Vietnam. Antimicrob Agents Chemother. 2009;53:3534-7.

11. Price RN, Hasugian AR, Ratcliff A, Siswantoro H, Purba HL, Kenangalem $\mathrm{E}$, et al. Clinical and pharmacological determinants of the therapeutic response to dihydroartemisinin-piperaquine for drug-resistant malaria. Antimicrob Agents Chemother. 2007:51:4090-7.

12. Wooden J, Kyes S, Sibley CH. PCR and strain identification in Plasmodium falciparum. Parasitol Today. 1993:9:303-5.

13. Viriyakosol S, Siripoon N, Petcharapirat C, Petcharapirat P, Jarra W, Thaithong S, et al. Genotyping of Plasmodium falciparum isolates by the polymerase chain reaction and potential uses in epidemiological studies. Bull World Health Organ. 1995;73:85-95.

14. Taylor SM, Parobek CM, DeConti DK, Kayentao K, Coulibaly SO, Greenwood BM, et al. Absence of putative artemisinin resistance mutations among Plasmodium falciparum in sub-Saharan Africa: a molecular epidemiologic study. J Infect Dis. 2015;211:680-8.

15. Menegon M, Pearce RJ, Inojosa WO, Pisani V, Abel PM, Matondo A, et al. Monitoring for multidrug-resistant Plasmodium falciparum isolates and analysis of pyrimethamine resistance evolution in Uige province, Angola. Trop Med Int Health. 2009;14:1251-7.

16. Duraisingh MT, Jones $P$, Sambou I, von Seidlein L, Pinder M, Warhurst DC. The tyrosine-86 allele of the pfmdr 1 gene of Plasmodium falciparum is associated with increased sensitivity to the anti-malarials mefloquine and artemisinin. Mol Biochem Parasitol. 2000;108:13-23.

17. Palmieri F, Petrosillo N, Paglia MG, Conte A, Goletti D, Pucillo LP, et al. Genetic confirmation of quinine-resistant Plasmodium falciparum malaria followed by postmalaria neurological syndrome in a traveler from Mozambique. J Clin Microbiol. 2004:42:5424-6.

18. Korsinczky M, Chen N, Kotecka B, Saul A, Rieckmann K, Cheng Q. Mutations in Plasmodium falciparum cytochrome $b$ that are associated with atovaquone resistance are located at a putative drug-binding site. Antimicrob Agents Chemother. 2000:44:2100-8.

19. Duru V, Khim N, Leang R, Kim S, Domergue A, Kloeung N, et al. Plasmodium falciparum dihydroartemisinin-piperaquine failures in Cambodia are associated with mutant K13 parasites presenting high survival rates in novel piperaquine in vitro assays: retrospective and prospective investigations. BMC Med. 2015;13:305.

\section{Submit your next manuscript to BioMed Central and we will help you at every step:}

- We accept pre-submission inquiries

- Our selector tool helps you to find the most relevant journal

- We provide round the clock customer support

- Convenient online submission

- Thorough peer review

- Inclusion in PubMed and all major indexing services

- Maximum visibility for your research

Submit your manuscript at www.biomedcentral com/submit 